\title{
Reseñas
}

\section{Común, o el principio de radicalización de la democracia}

Delia Langa Rosado'

Laval, Christian y Dardot, Pierre (2015): Común. Ensayo sobre la revolución en el siglo XXI (Barcelona, Gedisa). ISBN: 978-84-9784-880-0, 669 pp.

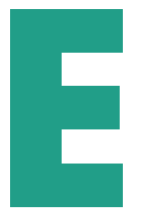

1 trabajo que ahora reseñamos parece responder a la esperada continuación del que en 2013 estos dos mismos autores publicaban La nueva razón del mundo (Gedisa) y que nos ofrecía un panorama social y político desoladoramente invadido por una nueva racionalidad, la de la gubernamentalidad neoliberal, sustentada sobre la construcción de nuevas subjetividades que asumen acríticamente la lógica de la competencia y la acumulación insaciable del capital, en la forma de sujetos empresarios de sí mismos. El concepto sobre el que versa este extenso tratado, “común”, en cambio, pretende aportar trazos que ayuden a dibujar la razón alternativa a la razón neoliberal. En efecto, los autores con esta obra quieren contribuir a la "emergencia estratégica" de lo común, como idea nuclear de una nueva racionalidad política que ellos vislumbran con potencial para superar la sociedad capitalista.

Ya es hora de desarrollar nuevas perspectivas sobre un más allá del capitalismo, de pensar las condiciones y las formas posibles de actuar en común, de extraer los principios capaces de orientar las luchas, de vincular las prácticas dispersas a la forma que pudiera adoptar una nueva institución general de las sociedades. (p. 20).

La propuesta de definición del concepto es pues pragmática y se aleja por ello de cualquier visión esencialista. Pragmática e insistimos, estratégica, pues parte de experiencias recientes de resistencia y transformación social que se vienen dando desde principios de siglo en diferentes lugares del planeta, para reformular un concepto que a su vez puede -consideran- retroalimentar esas mismas luchas. Esa es su apuesta, y lo que a nuestro juicio más valor concede a este libro.

Comienza el trabajo con una arqueología del término "común" que intenta depurar éste de cualquier definición reificadora. Muy sugerente en este sentido la negación de la acepción estatalizadora: lo común no es lo público estatal, constatados históricamente los límites burocratizadores y de apropiación privada a que hemos visto ha podido verse sometido. También se desmarcan los autores de la esencialización del concepto, desde luego en clave teológica, y, y quizá más interesante y actual, en clave naturalista (habría bienes que esencialmente son inapropiables), o humanista (apelando a un cierto universalismo inscrito en la propia naturaleza del ser humano).

1 Universidad de Jaén; dlanga@ujaen.es 
Tras esta declaración de intenciones, el libro aborda su objetivo a través de tres grandes bloques. El primero es más analítico e insiste profusamente en demarcar el concepto común, que emerge para ellos, como hemos dicho, de diferentes prácticas de transformación social para las que lo "común" resulta emblemático y aglutinador, pero que los autores quieren contribuir a reformular en clave crítica diferenciándolo de determinadas acepciones. Sugerente el capítulo inicial de esta parte, que titulan "la hipoteca comunista" en que apuntan al lastre que la concepción estatista de los países de socialismo real ha supuesto frente a las luchas emancipadoras en la segunda mitad del siglo xx.

Muy lúcidas, a continuación, las reflexiones en torno a los límites que el paradigma de los commons que utilizan como referente histórico los procesos de enclosure que tuvieron lugar entre los siglos XV y XIX en los campos europeos. La analogía con las nuevas enclosure tanto del ámbito de la creación intelectual (los derechos de la propiedad intelectual) como de los de la biodiversidad y el de los espacios públicos hasta hace poco preservados de la acumulación capitalista, resulta sugerente, valoran Laval y Dardot, como herramienta para explicar el carácter expropiador del capitalismo financiarizado, que sigue basándose en el pillaje como modo de desposesión. No obstante, para los autores las nuevas formas de dominio y explotación no se agotan en a estos procesos, sino que se sustentan también en la arquitectura de la gubernamentalidad neoliberal que necesita movilizar las subjetividades para aceptar este nuevo orden social, cultural y político.

De nuevo, y en relación con esto, resulta muy fecunda la lectura crítica que hacen de los trabajos de Ostrom. Se preguntan hasta qué punto la economía política aplicada al uso común cooperativo de determinados bienes naturales que son gestionados según una lógica distinta a la del mercado y a la estatal, en realidad ubican solo en la eficacia productiva el criterio que otorga a los comunes su carácter de tales. Laval y Dardot consideran que cuando se miran los nuevos comunes del conocimiento (el software libre, las enciclopedias colaborativas, la difusión libre de ciencia y arte, etc.) es donde más claramente se aprecian los límites no solo de esta deriva naturalista de la economía política, sino también de las visiones deterministas que otorgan a las nuevas tecnologías de por sí un potencial radical y transformador. Los comunes cognitivos son comunes -esto será de vital importancia en sus propuestas políticas- en cuanto son protegidos por determinados dispositivos institucionales de la comercialización y de la apropiación privada, o estatal. Son dispositivos (pensemos, por ejemplo, en el movimiento de los Creative Commons) donde se aúnan saberes técnicos y jurídicos que posibilitan formas cooperativas de creación y multiplicación de riqueza que en otras condiciones seguramente no tendrían lugar, o lo harían más deficientemente.

Precisamente el capítulo que dedican a la aportación de Hardt y Negri reconoce de éstos el gran salto político que con su obra contribuyen a dar haciendo que se pase de los commons al común en singular. El subrayar la importancia de la biopolítica y la nueva producción de subjetividades, que toma por ejemplo en las tecnologías de la evaluación y en la ideología del capital humano un contenido emblemático, no les impide a Hardt y Negri - a juicio de los autores de Común- adolecer de un cierto determinismo social, e incluso optimismo histórico, a la hora de elaborar el potencial transformador que a la postre tendría lo común, tal como Hardt y Negri lo plantean. En la estela de este trabajo de Laval y Dardot de hallar atisbos de posibles reificaciones del término, una falla más que se atreven a señalar, entendiendo que cualquier visión determinista será un importante impedimento para situar las nuevas luchas y prácticas colectivas de resistencia al capitalismo, con la impronta de radicalización democrática que les caracteriza -ahora lo veremos- como fuente de institución y de derecho de lo común.

Y es que para los autores de este tratado, en efecto, lo que está en juego es la afirmación de un derecho nuevo: lo común constituye el principio de un nuevo derecho destinado a refundar toda la organización de la sociedad, y entonces es 
el derecho de propiedad el que debe ser radicalmente cuestionado (p. 261). La parte segunda del libro es quizá la que se nos hace más pesada por lo prolija y específicamente destinada a contenidos jurídicos. Desde una genealogía del derecho de propiedad para apuntar a la falsa disyuntiva entre propiedad común y propiedad privada y en cambio señalar el carácter de inapropiabilidad que se instituiría en una sociedad basada en lo común; hasta una clara diferenciación del nuevo derecho de lo común del mero derecho consuetudinario; pasando por una profusa reflexión sobre el derecho de la pobreza que, aunque supone un espacio social preservado de los intereses de las clases dominantes, no deja de ser una forma de derecho de costumbre. Nosotros queremos detenernos en el capítulo dedicado al período del sindicalismo revolucionario francés en el siglo XIx y a las experiencias de las bolsas de trabajo en tanto que el análisis que hacen los autores, tomando la teoría del don de Marcel Mauss, resulta muy interesante y prefigura algunos de los elementos que serán nucleares para entender la propuesta política que al final elaboran Laval y Dardot. Nos resulta muy revelador el que éstos rescaten la experiencia obrera de cooperación y socialismo asociacionista así como la reflexión sociológica de alguien que además de su implicación intelectual se caracterizó por su actividad militante. La experiencia del sindicalismo revolucionario francés, a los ojos de Mauss, en efecto, implica la instauración del principio del don como un derecho social y la aplicación de una nueva moral de la solidaridad basada en el trabajo en común creando así espacios y realidades no capitalistas. El derecho sería la base de esta nueva fundación social, y el carácter social del derecho que inauguran estas experiencias no procedería como fuente exclusiva del legislador, del Estado, sino de la propia base de la sociedad. Apuesta federalista de organización social, económica y política, que nos trae sin duda ecos de Proudhon y sus principios autogestionarios y que nos lleva al último capítulo de esta segunda parte.

Quizá el cierre de este segundo bloque más jurídico es el que nos permite disfrutar más de la fecundidad de la reflexión sociológica de nuestros autores. Al preguntarse por el tipo de prácticas que pueden generar nueva normas de derecho rescatan un concepto sociológico central: el de institución. Obviamente esto nos remite a autores como Durkheim, pero, como era de esperar, para Laval y Dardot, lejos de esta perspectiva funcionalista, la institución remite más al acto de instituir que a lo instituido. Muy sugerente es la delimitación de los conceptos poder constituyente y poder instituyente, pues con ella los autores pretenden desmarcarse de la idea de que la institución está en todo momento determinada por la autoridad, por la soberanía. La institución como praxis instituyente toma en gran medida ideas de Castoriadis y su "imaginario radical" y en definitiva apunta a una concepción de lo social donde cobran centralidad los procesos de ruptura y la emergencia de nuevas significaciones. Lo instituyente, pues, frente a lo constituyente se aleja por tanto de determinismos tanto economicistas (donde la institución no se ve más que como fenómeno superestructural), pero también de concepciones esencialistas e identitarias que ubicarían necesariamente la soberanía en un pueblo preexistente. Lo social es la base colectiva y anónima del poder instituyente: poder de todos y poder de Nadie (Castoriadis), poder de los Cualquiera (si pensamos en Rancière). En defintiva, la centralidad del concepto institución así entendido les lleva a enunciar su propuesta: "la praxis emancipadora es praxis instituyente o actividad consciente de institución" (p. 499). La política es la actividad que tiene que ver con la institución de toda la sociedad, con la formulación de significaciones imaginarias, y para ser emancipadora, lo que proponen los autores, ha de ser participable por todos. Y entramos, pues, en el último bloque de este tratado, y en el tema de la radicalización de la democracia, nuclear en sus principios políticos.

Fieles al carácter emergente de la praxis del concepto que pretenden definir y a la intención estratégica que para ello han decidido darse, la última parte de esta extensa obra es, en efecto, una enumeración de propuestas políticas (en concreto son nueve) que dicen recoger, y animar, las experiencias y reflexiones de lucha social contra el actual estado neoliberal que se vienen dando desde el inicio de siglo. Todas 
ellas parecen señalar una nueva sensibilidad que apunta a una profundización en las distintas formas de democracia y a una clara desconfianza en los partidos y su engranaje en las dinámicas de representación parlamentaria.

Las propuestas que se declaran y enumeran en este bloque del libro se basan muchas de ellas en ejemplos de construcción de comunes en nuestra historia reciente ${ }^{2}$, a partir de las cuales se extraen principios que a su vez, en la formulación sintética que hacen Laval y Dardot, pretenden estimular el imaginario social y con ello la praxis instituyente de la transformación de la sociedad a gran escala a través de lo común. De estos principios vamos a recordar sumariamente algunos aspectos que nos parecen especialmente potentes.

En primer lugar, lo común remite al orden de la praxis, y es común porque es participable por todos, no solo por políticos profesionales, y expertos. Al ser pragmático el concepto, la obligación política procede del hacer en común, y no de la pertenencia identitaria, ya sea nacional, étnica, religiosa o de la humanidad incluso. De otro lado, lo común no implica un bien común predefinido, ni en el sentido moral ni en el sentido de la propiedad. En el sentido moral: el bien común es bien porque lo define el común y mientras lo define el común. La acepción de bien como propiedad queda, por otra parte, descartada pues el gobierno de lo común, niega la propiedad, instituye la inapropiabilidad de determinados recursos, cuyo uso se regula o su abuso se prohíbe. Pero es el proceder en común quien lo instituye. Es la praxis lo que tiene prioridad, praxis instituyente que busca gobernar a favor de lo común, superando los conflictos sociales que no obstante alimentarían esta praxis, generadora a su vez de la co-obligación de participar. El sujeto de la política así entendida es un sujeto colectivo, pero no es un todo homogéneo ni preexistente; somos todos y no es nadie, somos los cualquiera que adquirimos el carácter de sujeto en el acto.

Aunque no vamos a entrar en cada uno de los nueve principios políticos que se declaran y proponen, sí queremos hacer la excepción con la propuesta que se refiere a la reformulación de los servicios públicos. Pensamos que ello nos da pistas para reflexionar sobre el debate, tan candente siempre en nuestro país, en torno a los servicios educativos y su titularidad. En el caso de la escuela, señalan, correspondería a los poderes públicos garantizar las condiciones de prestación del servicio así como una financiación igualitaria de éste, pero la gestión podría bajar a niveles locales en donde la gente podría implicarse dando así materialidad a la nueva institución de lo común (lo participable por todos los concernidos) para hacer efectivo el derecho a una educación igualitaria. Quizá esto nos diera ciertas claves para hablar de lo común de la educación, de las condiciones políticas que garantizarían un uso justo e igualitario de estos servicios, y se evitarían los usos y abusos expresivos de lo educativo a los que nuestros políticos, en el caso del sistema educativo, nos tienen tan acostumbrados. Se trataría de devolver al servicio público la dimensión de común político, de repolitizar en este sentido el debate sobre la educación, y de hablar de cuestiones cómo el acceso desigual a unos u otros tipos de centros, los resultados desiguales, los factores que dan lugar a esto, y las medidas que se habrían de adoptar para vigilar y garantizar que con el dinero de todos, todos se beneficien en condiciones de igualdad, por ejemplo.

En definitiva, y volviendo al contenido general de la obra, la definición de común como principio político es una propuesta que aglutina muchas de las prácticas de movilización de estos últimos años, y que no nos parece muy difícil de reconocer en un país como el nuestro que ha gestado y protagonizado desde

2 Curiosa, por lo cercana que nos resulta, la referencia concreta a la ocupación de la finca cordobesa de Somonte por parte de sindicalistas del SAT en 2012. Se pone como ejemplo de praxis instituyente de lo común, como experiencia de codecisión económica en que la ocupación no implica una reivindicación de la propiedad de la tierra, sino una institucionalización del derecho de uso de ésta, ante la constatación de los años que llevaba siendo improductiva y la intención de la Junta de Andalucía de venderla y por tanto ser fuente de beneficio de los intereses especuladores. 
el 2011 toda una serie de manifestaciones y praxis que no hacen sino apuntar y profundizar en este tipo de sensibilidad. Resonancias quincemayistas, ecos de una tradición libertaria y autogestionaria que parece reverdecer ante los modos de vasallaje neoliberal que se nos pretenden hacer pasar por el único modo de ser: cooperación frente a individualismo y competencia; federación de lo común, de los comunes, sin sacralismos moralistas ni verdades preestablecidas; democracia real como apuesta para ampliar las cotas de libertades individuales a las que sin duda no estamos dispuestos a renunciar muchos de nosotros, aunque de algunas solo vaya quedando el recuerdo, y defensa al mismo tiempo de libertades colectivas que pasan por una sociedad más igualitaria y con un poder más distribuido. De agradecer, pues, este trabajo honesto, valiente y necesario de Laval y Dardot, que quizá tenga en su carácter prolijo su peor reclamo, pero que debería darse a conocer como lectura sugerente y fecunda. Leer sus reflexiones y el modo pragmático en que las presentan, nos hace palpar el pulso, y pensar sobre el alcance ${ }^{3}$, de una nueva sensibilidad política que apunta a la rotunda obviedad, cada vez más instalada como ideal o aspiración en nuestra sociedad, de que las cosas de todos sin duda entre todos serán mejor gobernadas. Mejor desde luego que lo que nuestra historia más reciente nos está demostrando, con sus terribles estragos de empobrecimiento de amplias masas de población, depredación del medio y concentración de poder y desgobierno para la mayoría.

3 También sus límites. La lectura de este ingente tratado da bastantes claves para identificar un tipo de uso o apelación a lo común que resulta inocuo y desde luego trivial, cuando no desmovilizador, en su capacidad transformadora. Pensemos en todos aquellos intentos de utilizar el término como mantra de la nueva política cuando no van acompañados de medidas y apuestas que objetivamente instituyan praxis más democráticas. 